\title{
Investigation of formalin and ethepon in some fruits of three local markets of Mymensingh district using gas chromatograph
}

\author{
M. A. Islam*, M. E. Haque and M. K. Hossain and M. S. Hossen \\ Department of Environmental Science, Bangladesh Agricultural University, Mymensingh-2202, Bangladesh \\ *E-mail-maislam@bau.edu.bd
}

\begin{abstract}
The presence of formalin and ethepon was investigated in some fruits viz. Apple, Banana and Mango collected from three local markets viz. Bangladesh Agricultural University (BAU) KR Market, BAU Shesh More market and Notun Bazar of Mymensingh Sadar. Samples were analyzed by gas chromatograph coupled with flame ionization detector. Data were tested in indentical condition with proper calibration of the instrument. Of the samples, 67 percent were free from both chemicals. About 10 ppm formalin was detected in the apple samples of BAU Shesh More. In contrast, $32 \mathrm{ppm}$ ethepon was quantified in the banana samples of BAU KR market.
\end{abstract}

Keywords: Formalin, Ethepon, Gas Chromatography, Fruits

\section{Introduction}

Food safety is an important public health concern in both developed and developing countries. Now-adays food is produced and distributed in a global market leading to stringent legislation and regulation for food quality and safety in order to protect consumers and ensure fair trade (Nielen and Marvin, 2008). Unfortunately food contamination and food adulteration are considered to be common occurrences in Bangladesh and concerns regarding food safety are frequently raised in the local media. Majority of foods available in the market contain different types of additives, among which preservatives are playing an important role. These additives, applied in order to maintain food quality, reduce food deterioration and prolong storage time, often make consumers anxious about its safety (Russell and Gould, 2003). Some food preservation methods such as drying, salting, sugaring, heating and they have long been used to prolong the shelf-life of foods. They are widely used in soy sauce, candy, preserved fruit, meat products, cheese, butter, margarine, juice, and baked goods (Lin and Choong, 1999).

Fruits are important components of the human diet since they provide essential nutrients that are required for most of the reactions occurring in the body. A high intake of fruits has been encouraged not only to prevent consequences due to vitamin deficiency but also to reduce the incidence of major diseases such as cancer, cardiovascular diseases and obesity. In order to reduce the loss and maintain the quality of fruits additives especially preservatives are applied in order to maintain food quality and prolong storage time. (Keikotlhaile and Spanoghe, 2011). Food which is over-fortified with additives such as preservatives, antioxidants, and sweeteners, or the inadequate use of food additives could adversely affect human health as they are consumed. Therefore, the identification and quantification of food additives are important in terms of food additive inspection (Lin and Choong, 1999).

Chromatography is an analytical technique which has been used for isolation, purification and separation of organic and inorganic compounds including qualitative and quantitative estimation of compounds. The volatile organic compounds (VOCs), poly-aromatic hydrocarbon and pesticides have been analyzed by gas chromatography-mass spectrometric technique (Sukesh and Bhatnagar, 2012). In this study, Gas chromatography coupled with flame ionization detector (GC-FID) is used for quantification of presence of formalin and ethepon in some selected fruits. The main objectives of this study were to explore the existing condition of fruits (Apple, Mango and Banana) in local market and to quantify chemical contamination in samples.

\section{Materials and Methods}

\section{Site selection}

Fruit samples were collected from three markets namely, a) BAU shesh more market, b) BAU KR market and c) Notun bazaar, Mymensingh Sadar upazilla. 


\section{Sample collection}

Three selected fruits viz. Mango, Apple and Banana were collected randomly on July 14, 2013. Aluminum foil was used just after sample collection to prevent evaporation from the existing condition of the sample.

\section{Extraction of samples}

The collected samples were extracted by liquid extraction technique reported by Fernandes et al. (2011) and Usher \& Majors (2013) with modification. The collected samples were cut into small pieces with proper labeling (Table 1) for future identification and kept in deep freezer $\left(-20^{\circ} \mathrm{C}\right)$. About $2 \mathrm{~g}$ of each sample (frozen part) was ground by hand grinder then allowed in $5 \mathrm{~mL} \mathrm{Hx}$ ( $\mathrm{n}$-Hexane) in test tube for 15 minutes and tightly closed by cork to avoid the evaporation of solvents and volatile chemicals. After 15 minutes, each part was mixed well by shaking and kept 5 minutes for stabling the mixture. The supernatant solution ( $\mathrm{Hx}$ with extracted compound) was taken in a vial by small glass pipette carefully. The vial was kept for further analysis.

Table 1. Fruit samples collected from three local markets of Mymensingh Sadar upazilla

\begin{tabular}{|c|c|c|}
\hline Sample ID & Sample name & Location \\
\hline FM1 & \multirow{3}{*}{ Mango } & BAU shesh more \\
\hline FM2 & & BAU KR market \\
\hline FM3 & & Notun Bazar, Mymensingh town \\
\hline FB1 & \multirow{3}{*}{ Banana } & BAU shesh more \\
\hline FB2 & & BAU KR market \\
\hline FB3 & & Notun Bazar, Mymensingh town \\
\hline FA1 & \multirow{3}{*}{ Apple } & BAU shesh more \\
\hline FA2 & & BAU KR market \\
\hline FA3 & & Notun Bazar, Mymensingh town \\
\hline
\end{tabular}

\section{Gas chromatographic analysis}

Prepared samples were analyzed by a Gas Chromatograph (GC) [GC-2014] Shimadzu Corporation, Kyoto, Japan. FID (Flame Ionization Detector) was used in this experiment. The overall GC conditions are given below:

\begin{tabular}{|c|c|c|c|}
\hline \multicolumn{4}{|c|}{ GC condition } \\
\hline & & GC/DFID & Stability/Reproducibility \\
\hline \multicolumn{2}{|c|}{ Column: } & $\begin{array}{l}\text { RT-Mseive 5A, serial number: } 1104596 . \text { Length: } 30 \mathrm{~m}, \\
\text { Inner diameter: } 0.53 \mathrm{~mm} \text {, } \\
\text { Film thickness: } 50.00 \mathrm{um} \text {. }\end{array}$ & $\begin{array}{l}\text { Column flow: } 6.63 \mathrm{~mL} / \mathrm{min} \\
\text { Maximum temperature: } 300^{\circ} \mathrm{C} \text {. }\end{array}$ \\
\hline \multirow{2}{*}{ Oven: } & Formalin & $\begin{array}{l}50^{\circ} \mathrm{C}(3 \mathrm{~min}) \text {, to } 200^{\circ} \mathrm{C} \text { at } 10^{\circ} \mathrm{C} / \mathrm{min} \text {, to } 300^{\circ} \mathrm{C} \text { at } \\
15^{\circ} \mathrm{C} / \mathrm{min} \text { and hold finally } 5 \mathrm{~min} \text {. }\end{array}$ & Column oven: $50^{\circ} \mathrm{C}$ \\
\hline & Ethepon & $\begin{array}{l}60^{\circ} \mathrm{C}(5 \mathrm{~min}) \text {, to } 220^{\circ} \mathrm{C} \text { at } 10^{\circ} \mathrm{C} / \mathrm{min} \text {, to } 280^{\circ} \mathrm{C} \text { at } \\
15^{\circ} \mathrm{C} / \mathrm{min} \text { and hold finally } 5 \mathrm{~min} \text {. }\end{array}$ & Column oven: $60^{\circ} \mathrm{C}$ \\
\hline \multicolumn{2}{|c|}{ Carrier: } & Hydrogen $(30 \mathrm{~mL} / \mathrm{min})$, Air (142.1 mL/min) & Hydrogen (30 ml/min), \\
\hline \multicolumn{2}{|c|}{ Detection: } & $\begin{array}{l}\text { DFID, } 300^{\circ} \mathrm{C} \text { (for Formalin), } 280^{\circ} \mathrm{C} \text { (for Ethepon), } \\
\text { Sampling rate: } 40 \mathrm{msec} \text {. }\end{array}$ & DFID, $300^{\circ} \mathrm{C}$ \\
\hline \multicolumn{2}{|c|}{ Injection: } & $1 \mu \mathrm{L}$, Direct injection, $200^{\circ} \mathrm{C}$ & Split \\
\hline \multicolumn{2}{|c|}{ Linear velocity } & $60.7 \mathrm{~cm} / \mathrm{sec}$ & Pressure: $66.8 \mathrm{kPa}$ \\
\hline \multicolumn{2}{|c|}{ Purge Flow } & $3.0 \mathrm{~mL} / \mathrm{min}$ & Split ratio: 20 \\
\hline
\end{tabular}

\section{Standard Chemicals}

The formaldehyde solution (GR-grade) (EM Science, Gibbs-town, NJ) consisting of approximately 36.5$38 \%$ formaldehyde; $10-15 \%$ methanol; $47-53.5 \%$ water; and trace amounts of chloride, sulfate, and heavy metals was used as the source of formaldehyde. Ethepon $48 \%$ solution was used as another standard solution, which was used for fruit ripening artificially. Injection of each standard solution was done (at least for 5 times) to confirm the retention time. 


\section{Data processing and analysis}

Different concentration of both standard solutions were injected in GC system under above mentioned condition and made calibration curve using known concentration. Calibration curve was made by MS Excel program using scattered diagram followed by regression line.

\section{Results and Discussion}

\section{Calibration of standard formalin solution}

During making a calibration curve with the standard solutions areas of peaks for every concentration were calculated. Single peak for different concentrations of formalin was observed (Fig. 1; left part) and a normal standard straight line was drawn using formalin content and peak areas (Fig. 1; right part).
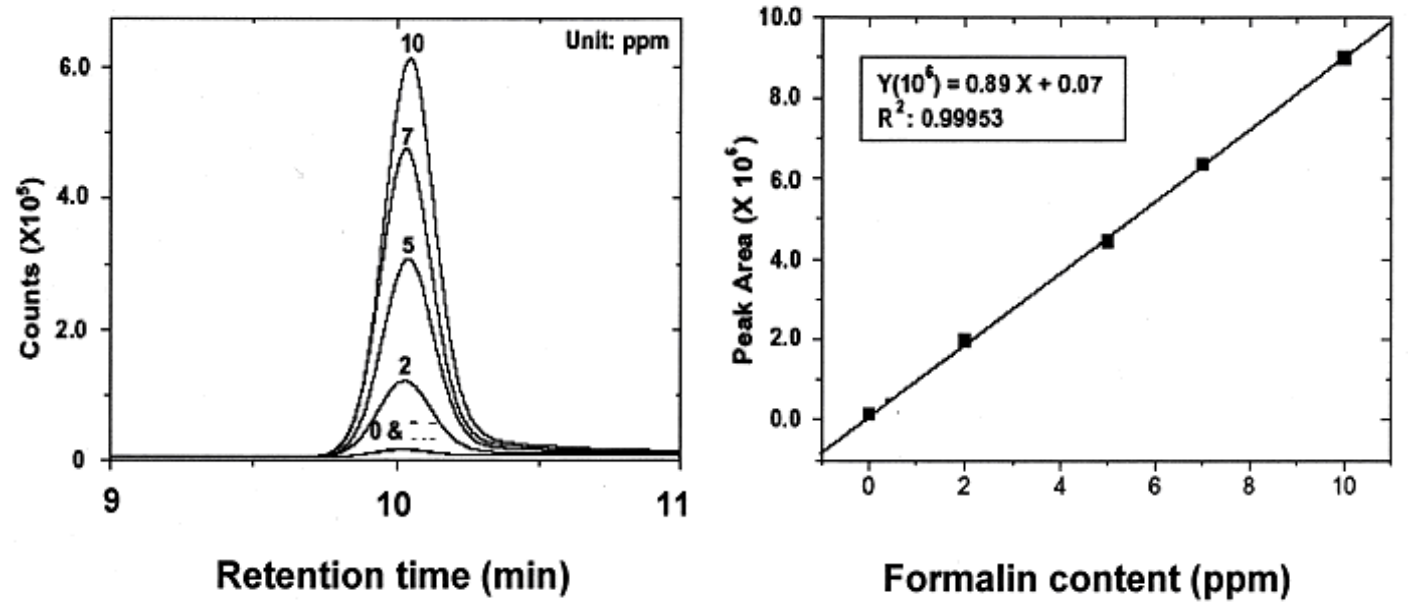

Fig. 1. Single ion monitoring (SIM) and calibration curve for formalin determination

\section{Calibration of standard ethepon solution}

Different concentrations of standard ethepon solutions were observed at 9.45 minutes and calibration curves prepared by using those data (Fig. 2). During making a calibration curve with the standard solutions areas of peaks for every concentration were calculated. The calibration curve showed the relationship between concentration of ethepon and peak area $\left(10^{6}\right)$ (Fig. 2).

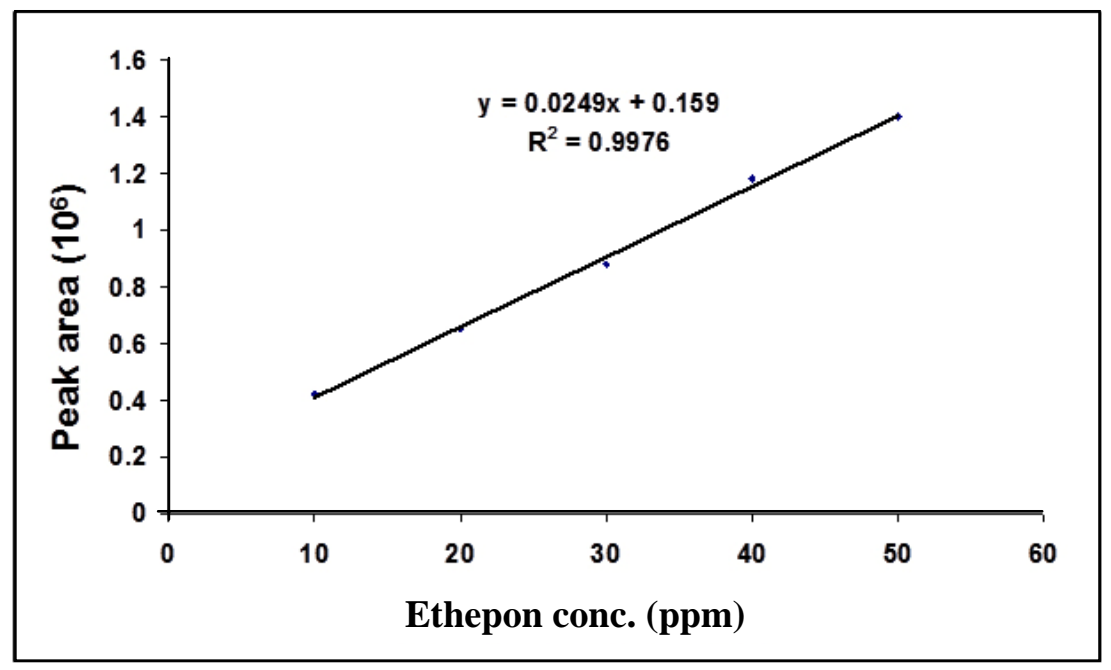

Fig. 2. Calibration curve for ethepon determination 


\section{GC analysis of standard formalin solution}

In GC analysis, standard formalin solution showed the response at 9.96 minutes. When the eluted retention time was fixed at 9.96 minutes for every injection of standard formalin solution then it was confirmed for the peak for standard formalin, which was shown in Fig. 1.

\section{GC analysis of apple samples}

When the extracted samples were injected in the analytical tools (GC) then most of the samples did not show such reasonable peaks. There was no such response observed due to absence of such analytical compounds in the samples or any other difficulties occurred during the process from sampling to analysis. But, one extracted sample (FA1) eluted many peaks within 6 to 12 minutes but the areas were negligible (Fig. 3a). The dilution of the sample may cause the less response of analysis. That's why more concentrated sample (FA1) injected again to elucidate similar types of peaks with great response and remarkable area. Then the elucidated peaks and their retention times were compared with standard formalin data, where 9.97 minute elucidated compound found (Fig. 3b) due to the presence of formalin in that sample.

(a)

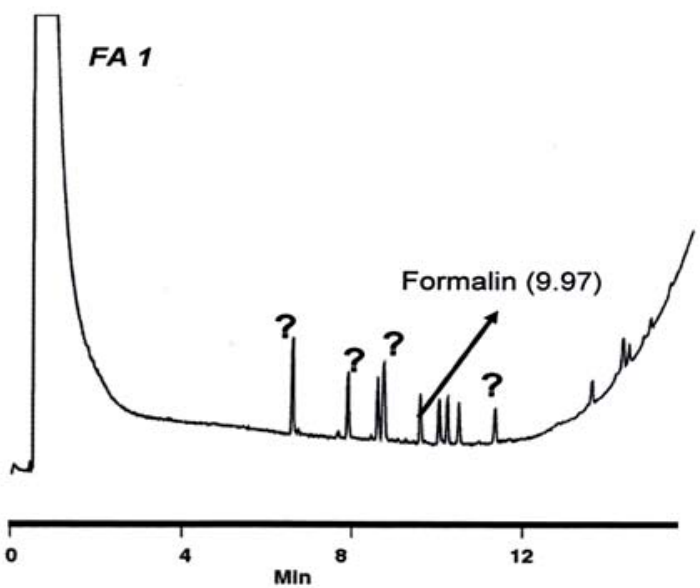

(b)

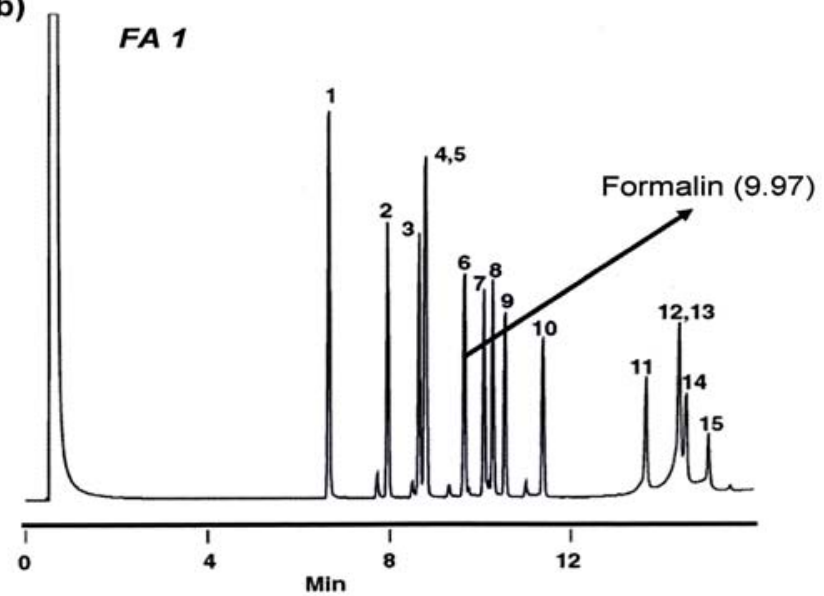

Fig. 3. Chromatograms showing the quantification of formalin of apple sample (FA1); (a). diluted sample showing peaks, Question marks (?) indicate the unknown elutions / peaks of the crude mixture of the banana sample. (b). More concentrated sample showing clear comparison between peaks. Numbers at the top of the peaks indicate the unknown compounds of the crude mixture of the apple sample.

In apple sample FA1, the residues of formalin were found in the concentration of $10 \mathrm{ppm}$. In apple sample FA2 and FA3, the residues of formalin were not found. Usher and Majors (2013) found the limit of quantitation for the pesticide residues was $10 \mathrm{ng} / \mathrm{g}$ in apple. At $200 \mathrm{ng} / \mathrm{g}$, the recoveries ranged from $89 \%$ to $102 \%$, and at $10 \mathrm{ng} / \mathrm{g}$, the recoveries ranged from $72 \%$ to $103 \%$.

\section{GC analysis of standard ethepon solution}

In GC analysis, standard ethepon solution showed the response at 9.45 minutes, which was repeated for at least 5 times. When the eluted retention time was fixed at 9.45 minutes then researcher confirmed about the peak for standard ethepon.

\section{GC analysis of banana samples}

Another fruit sample (FB1) showed a minute response for ethepon at 9.43 minutes which was identical with previous results. FB3 sample showed distinguished peaks at 9.43 minutes which was also identifiable with ethepon standard solution (Fig. 4). In banana sample FB1, the residues of ethepon was found at very minute level (Fig. 4a) and in sample FB2, no residue of ethepon was found. In banana sample FB3, the concentration of the residues of ethepon was $32 \mathrm{ppm}$ (Fig. 4b). Paranthaman et al. (2012) found carbendazim in banana samples, at concentrations ranging from $0.002-0.11 \mathrm{mg} \mathrm{kg}^{-1}$. 


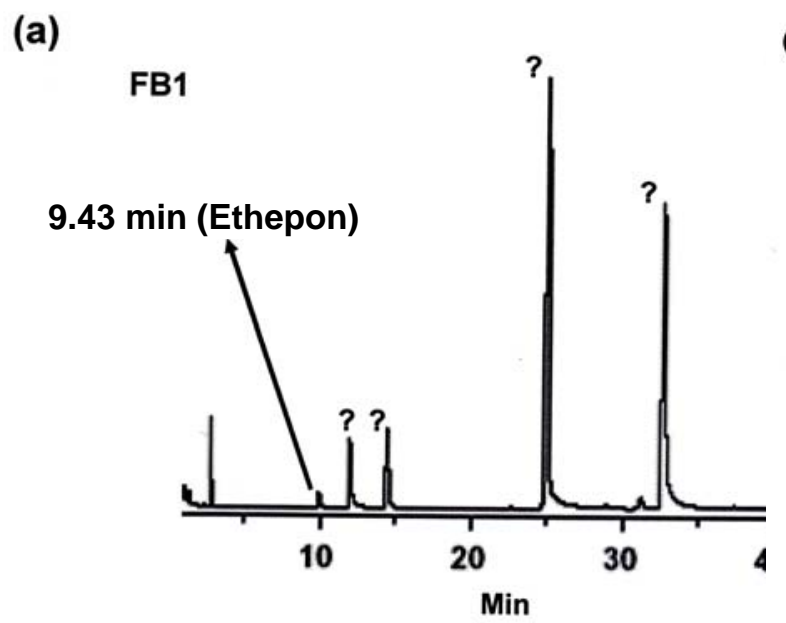

(b) FB3

Fig. 4. Chromatograms showing the quantification of ethepon of banana samples (FB1 and FB3).

\section{GC analysis of mango samples}

In mango sample FM1, FM2 and FM3 the residues of formalin were not found. Hussain et al. (2002) determined the pesticide residues in mango samples collected from the fields of farmers in Multan division. In this study three varieties of mango samples, sample I (Dusehri), sample II (Chaunsa) and sample III (Sindhri) were analyzed for 6 pesticides namely Cypermethrin, Methamedophos, Monocrotophos, Cyfluthrin, Dialdrin and Methyl Parathian. It was observed that all the samples were contaminated with pesticides.

The above data show that fruits sample collected from different sites were contaminated with chemicals but some samples have no detectable residues. Out of 9 samples, 6 samples (67\%) were free from pesticide residues and $3(33.33 \%)$ samples were contaminated with chemicals (formalin and ethepon), which were used for post-harvest activities. The rate of contamination of different chemicals varied from 0 to $86 \%$ in fruits, like- dithiocarbamates (15.1\% of 397 samples), dimethoate (6.8\%), tetradifon (4.5\%), Malathion (3.3\%), Chlorothalonil (2.0\%) (Salwa et al.,1999).

\section{Conclusion}

Results revealed only 3 samples (out of 9 samples) responded to chemical contaminations. One peak was found in apple sample of BAU Shesh More market which was same as formalin peak. The quantity of the formalin residue of that sample was about $10 \mathrm{ppm}$. On the other hand, out of 3 banana samples, 2 of them showed the presence of chemical residues. One peak was identified in banana sample of $B A U$ Shesh More and Mymensingh Notun Bazar market which was same as ethepon peak. But sample from BAU Shesh More eluted a small area contained peak which was very minute amount (less than $0.1 \mathrm{ppm}$ ). Banana sample from Mymensingh Notun Bazar market showed a remarkable peak which was approximately $32 \mathrm{ppm}$ of ethepon residue. Chemical residues were not found in other 6 samples.

The following recommendations would be helpful to overcome the presence of chemical residues in local market products: 1) Legal authority should monitor the residual effect of fruits in local market; 2) Government should formulate a policy that will restrict the use and availability of chemicals; 3 ) the common people should careful about pesticide residual effect. 


\section{References}

Keikotlhaile, B. M. and Spanoghe, P. 2011. Pesticide Residues in Fruits and Vegetables, Pesticides - Formulations, Effects, Fate, Prof. Margarita Stoytcheva (Ed.), Retrieved from: http://www.intechopen.com/books/pesticides-formulations-effectsfate/pesticide-residues-in-fruits-andvegetables.

Fernandes, V. C., Valentina, F., Domingues, V. F., Mateus, N. and Matos. C. D. 2011. Determination of Pesticides in Fruit and Fruit Juices by Chromatographic Methods - An Overview. Journal of Chromatographic Science, 49.

Lin, H. J. and Choong, Y. M., 1999. A Simple Method for the Simultaneous Determination of Various Preservatives in Liquid Foods, Journal of Food and Drug Analysis, 7(4): 291-304.

Paranthaman, R., Sudha, A. and Kumaravel, S. 2012. Determination of Pesticide Residues in Banana by Using High Performance Liquid Chromatography and Gas Chromatography-Mass Spectrometry. American Journal of Biochemistry and Biotechnology, 8 (1): 1-6.

Nielen, M.W.F. and Marvin, H. J.P. 2008. Challenges in Chemical Food Contaminants and Residue Analysis. Comprehensive Analytical Chemistry, 51: 2-27.

Russell, N.J. and Gould, G.W. 2003. Food preservatives, ed. .Kluwer Academic/Plenum Publishers, New York.

Salwa, M., Dogheim, A., Gad A. S. and Ashraf, M. E. 1999. Monitoring pesticide residues in Egyptian fruit and vegetables. J. Offic. Associ. Analyt. Chem., 82 (4): 948-955.

Sukesh N. S. and Bhatnagar, V. K. 2012. Analysis of Toxicants by Gas Chromatography Advanced Gas Chromatography - Progress in Agricultural, Biomedical and Industrial Applications, 978-953.

Usher, K. and Majors, R. E. 2013. Analysis of Pesticide Residues in Apple by GC/MS using Agilent Bond Elut QuEChERS Kits for Pre-injection Cleanup. Application Note, Agilent Technologies, 54-98.

Zhao, L., Schultz, D. and Stevens, J. 2013. Analysis of Pesticide Residues in Apple Using Agilent Bond Elut QuEChERS AOAC Kits by GC/MS. Application Note, Agilent Technologies, P. 67-89. 